\title{
Entrevista com \\ João Paulo Borges Coelho
}

\author{
Rita Chaves \\ Universidade de São Paulo
}

RESUMO: AO LONGO DE 2009, COM UMA BOLSA DA CAPES, PUDE DESENVOLVER JUNTO À UNIVERSIDADE EDUARDO MONDLANE UMA PESQUISA INTITULADA ASPECTOS E PROBLEMAS DO ROMANCE EM MOÇAMBIQUE E ANGOLA NA CONTEMPORANEIDADE. DURANTE OS NOVE MESES, O PROF. DR. JOÃO PAULO BORGES COELHO, DA FACULDADE DE LETRAS, FOI O PARCEIRO INSTITUCIONAL E O INTELECTUAL - AÍ INCLUINDO-SE NATURALMENTE O ESCRITOR - E O PRINCIPAL INTERLOCUTOR. DAS LONGAS CONVERSAS, ENTRE OS MUITOS E EFETIVOS RESULTADOS PARA O TRABALHO, FICOU A ENTREVISTA A SEGUIR.

ABSTRACT: DURING THE YEAR OF 2009 I WAS GRANTED A SCHOLARSHIP FROM THE BRAZILIAN FEDERAL AGENCY "CAPES", BY WHICH I WAS ABLE TO DEVELOP A RESEARCH AT EDUARDO MONDLANE UNIVERSITY (MAPUTO), WHICH WAS ENTITLED "ASPECTS AND PROBLEMS OF THE NOVEL IN MOZAMBIQUE AND ANGOLA IN THE CONTEMPORANEITY". DURING NINE MONTHS, THE PROFESSOR PHD. JOÃO PAULO BORGES COELHO, FROM LANGUAGES DEPT., WAS MY INSTITUTIONAL AND INTELECTUAL PARTNER - BESIDES, OF COURSE, HIS ROLE AS A WRITER - BY BECOMING MY MAIN INTERLOCUTOR. FROM OUR LONG AND PROFITABLE CONVERSATIONS, IT REMAINS THIS INTERVIEW.

PALAVRAS-CHAVE: LITERATURA, MOÇAMBIQUE, JOÃO PAULO BORGES COELHO, ENTREVISTA.

KEYWORDS: LITERATURE, MOZAMBIQUE, JOÃO PAULO BORGES COELHO, INTERVIEW. 
ita Chaves: Num cenário em que o oficio de escritor é frequentemente exercido com precocidade, você faz o contraponto. Estrear com base numa maturidade foi uma escolha on aconteceu?

João Paulo: Claramente, aconteceu. Muitas vezes me perguntam por que "acumulei" material durante tanto tempo sem o publicar, mas o facto é que nada acumulei. Na juventude li compulsivamente, escrevi alguns contos, muitos poemas medíocres, mas depois atravessei duas décadas em que a escrita me rondou como uma sombra que por vezes aflorava sem chegar nunca a concretizar-se. Não posso dizer-lhe as razões, uma vez que não estou certo delas. Em parte, talvez devido ao contexto fechado e monotemático que se vivia na década de 1980 , em que, certamente por falha minha, não fui capaz de achar uma voz, palavras que me fossem próprias. Também é certo que nessa altura não segui por caminhos literários que só ocasionalmente me tentavam, porque havia outros trabalhos suficientemente aliciantes para absorver a mente e o quotidiano, trabalhos esses ligados à universidade a que pertenço e ao pensar e agir no país desse tempo, que era muito empolgante. A partir de certa altura, talvez por meados da década de 1990, houve transformações importantes: por um lado (e paradoxalmente, uma vez que é um período de abertura democrática) a universidade perdeu brilho, tornou-se mais cinzenta, menos irreverente, trocando a criatividade que a independência lhe trouxera por uma ordem mais formal e hierarquizada, onde o espaço de discussão foi reduzindo, e isso levou de alguma maneira a que me afastasse, não no sentido profissional, mas espiritual (passei a distinguir mais o meu tempo privado, que antes se fundia inteiramente com o dela). Por outro lado, cheguei a uma verdade simples, que todavia levou muito tempo a ser-me revelada: a de que a vOz da escrita é profundamente individual e encontra a sua razão na diferença, não no coro. Quanto à maturidade, é uma palavra de que desconfio e que só parcialmente integro neste processo, apenas no que pressupõe de sentido de pertença à literatura no sentido mais lato (a escrita, cada vez mais, tem de ser um acto reflectido, e portanto culto), de consciência social mais serena e menos iludida, de critério estético mais apoiado - tudo aquilo que, bem ou mal, se obtém naturalmente com o passar do tempo, com a idade. Maturidade no sentido em que escrever é uma prática tornada necessária, e não a urgência febril de cumprir uma missão ou fazer passar uma mensagem. Quanto ao resto, não 
me sinto próximo da maturidade. Na escrita de ficção há sempre a surpresa, uma insegurança juvenil, ingredientes que estão do lado oposto da maturidade. O que procuro na escrita está mais próximo da curiosidade e da descoberta do que da conclusão ou do ensinamento. As incertezas vão mudando mas continuam lá, tão vincadas como sempre. Talvez possa dizer, para lhe responder, que a partir de certa altura foi uma escolha, que continua acontecendo.

Rita Chaves: Em que medida a atividade de historiador marcou a atividade literária? Por exemplo, a escolha do romance como gênero primordial na sua produção está, por você, associada a essa convergência?

João Paulo: Certamente que haverá traços da actividade de historiador na minha prática literária: no talvez excessivo rigor na localização do espaçotempo das tramas, nas estruturas causais das explicações etc. Todavia, não vejo a literatura como complemento do discurso histórico ("dizer pela ficção aquilo que a história não seria capaz de dizer”), longe disso! Pelo contrário, procurei a literatura como quem procura, não a complementaridade, mas o contraste. A história está sujeita ao paradigma da verdade, procura ser objectiva, ao passo que a literatura está mais próxima da imaginação e da intuição. Certamente que a imaginação também joga um papel fundamental da prática historiográfica, mas trata-se de uma imaginação responsável, freada, que se solta para logo em seguida a procurarmos controlar. Na literatura a imaginação tem mais espaço, menos responsabilidade, assombrada apenas por uma coisa que ainda não sei bem o que é e se chama verossimilhança, e por necessidades éticas nem sempre claras. Por outro lado, não sinto a formação em história como razão particular da minha opção pelo romance. O romance é a maneira que tenho de respirar a escrita. Acredito que quem escreve tem um respirar específico, e julgo que o meu é esse. Percebo, na base da relação que me coloca o facto de ambos - historiografia e romance - serem narrativas "fechadas". Mas, no que me diz respeito, parto para o romance com uma ideia que pode resumir-se em um ou dois parágrafos, ou com a vontade de aprisionar o sentido de um tempo, nunca com um plano detalhado. $\mathrm{O}$ resto vai surgindo intuitivamente, influenciado pela prática diária da escrita, por secretas influências quotidianas, estados de espírito, acasos. Sei como começa, nunca como acaba. Para mim, muito mais importante do que ter uma história 
escrita é o acto de a escrever (de a ir descobrindo). O segredo está em manter no ar a frágil borboleta, fazendo confluir subtis correntes de ar para as suas asas; ou mesmo, quando necessário, soprando-lhe gentilmente. Esse labor torna-se mais difícil à medida que a obra caminha para o desfecho e se vão esgotando as possibilidades alternativas (à medida que o ar se vai rarefazendo). Há que manter essas possibilidades em aberto até onde for possível, fazer durar as significâncias, impedir que se tornem impostas certezas. O ideal é que a história termine com a visão da borboleta perdendo-se na distância, sempre no ar. Aspirar a que a leitura tome conta do voo que já não podemos guiar. A historiografia interpreta enquanto o romance, aberto, dispõe.

Rita Chaves: O caminho da fiçãa pode ser lido como complementar à função documental e reflexiva que a história como disciplina propõe ou o seu percurso traduz. uma espécie de desencanto com a ciência? Ou com o modo de fazer ciência?

João Paulo: Tentei, atrás, distinguir os dois campos - a história e a ficção - quer no que me diz respeito, quer de um ponto de vista por assim dizer mais geral. Talvez possa acrescentar agora, no sentido inverso, que há também muitos aspectos em que eles se aproximam. Num livro autobiográfico intitulado Errata: Revisões de uma vida, o pensador George Steiner, de uma forma algo radical, nega às Humanidades a possibilidade de ascender à teoria. Diz ele: "Tenho para mim que a invocação da 'teoria' relativamente às humanidades, aos estudos históricos e sociais, à avaliação da literatura e das artes, é uma intrujice. As bumanidades não são susceptiveis de demonstração nem de verificação (excepto ao nivel material, documental). As nossas respostas ao seu estudo são narrativas de intuição. Na dinâmica desenfreada da semântica, no fluxo da significação, no jogo ilimitado das interpretações, as únicas proposições são as de escolha e gosto pessoal, de afinidade incoativa ou de surdez. Não pode haver refutações ou infirmações em qualquer sentido teórico. Coleridge não refuta Samuel Johnson; Picasso não supera Rafael. Nas letras humanas, a 'teoria' não passa de intuição que se tornou impaciente". Embora não partilhe inteiramente desta visão radical, intuo nela algo de verdadeiro, por exemplo no sentido em que a historiografia não deixa de ser uma "narrativa de intuição" particularmente vulnerável à interferência ideológica e política. O nosso caso é particularmente ilustrativo. Sendo o passado um poderoso factor de estruturação do presente, trinta e cinco anos depois da independência os arquivos documentais continuam fechados, inacessíveis, e a História demasia- 
do refém das interferências do político e do ideológico. Esta situação torna a prática da historiografia uma fonte não propriamente de desencanto mas de dificuldade e paciência. O que, de uma certa maneira, lhe redobra a importância e o que ela tem de desafio. Dito isto, não vejo, ao nível da minha prática pessoal (e já o disse mais do que uma vez), que história e ficção sejam complementares, mas antes expressões e práticas independentes, embora numa perspectiva mais geral de interpretação da vida, elas, sem dúvida, se complementem no sentido em que nenhuma pode dar conta sozinha desse tão fundamental empreendimento. Não me move um sentido de missão, mas de existência e experimentação. Se pudesse, se fosse mais jovem e os dias mais compridos, sem dúvida pintaria e aprenderia a tocar um instrumento musical, tentando viver todas essas experiências sem a preocupação de as relacionar umas com as outras a fim de fabricar uma mensagem.

Rita Chaves: Uma das características de seus textos é a pluralidade de espaços. Os dois volumes de Índicos Indicios parecem apontar para uma vontade de percorrer ficcionalmente o país. Isso pode ser visto como um projeto ou apenas como uma tradução do gosto pela viagem?

João Paulo: Cada livro é uma experiência nova, e a experiência dos Índicos Indícios foi-me particularmente cara. Nela procurei tratar o espaço tanto sob o ponto de vista dos lugares como dos itinerários para chegar até eles. De facto, tendo partido da perspectiva de encontrar os lugares, descobri, nesse labor, que os itinerários, além de espaços brancos de transição para chegar aos lugares podem ser também sucessões infinitas e contíguas de lugares dotados de existência própria e só vagamente percebidos na passagem (não é a linha uma sucessão de pontos?). Não diria que tenho a intenção de fazer uma cartografia sistemática do país, embora os Índicos Indícios possam levar a tal ideia. O espaço nacional tem uma importância relativa na medida em que eu podia ter incluído narrações suscitadas por Bagamoyo (na Tanzania) ou Swakopmund (na Namíbia), por exemplo. O fio que unia estas contas era o mar, e sinto que tenho ainda para explorar o enigma da relação conflituosa que África tem com o mar (será por este ter tragado sucessivas ondas de escravos?). Vários textos me haviam já alertado para a importância destas questões relativas a lugares e a itinerários, questões não propriamente de viagem, mas suscitadas pela viagem: as fantasmáticas movimentações de obscuros personagens 
de Borges (muitas delas de noite ou ao lusco-fusco, em cima de cavalos e aportando a estalagens); os intricados percursos entre Lisboa e Luanda do Lobo Antunes do Boa Tarde às Coisas Aqui em Baixo; a solitária deambulação de Michael K num mundo feito de escombros, em JM Coetzee; a dolorosa cartografia de Terezín levada a cabo pelo Austerlits, de W.G. Sebald; a claustrofóbica Oran de Camus; o espantoso hino aos lugares que são os quatro volumes do Quarteto de Alexandria de Lawrence Durrell. A lista é interminável. Ainda, num nível diferente, Haidegger e Deleuze. O meu projecto estava contudo longe de tentar articular tais influências: consistia simplesmente em ficar imóvel, em cada lugar, até sentir o som do seu respirar; até descobrir, entre as pedras e arbustos, nas casas e nas suas sombras, ou no ar, os vultos furtivos que os habitam, de que forma os lugares interferem nos enredos humanos e estes, por sua vez, ajudam a imprimir um perfil aos lugares. No fundo, fazia também parte da intenção, reconheço, divulgar os lugares e os seus nomes, para dar vazão a uma obsessão que me persegue, em torno da injustiça de alguns lugares serem muito falados enquanto outros permanecem imersos na obscuridade do desconhecimento. Amo a viagem, mas infelizmente sou um viajante demasiado prudente. Reconheço que, na maioria dos casos, não escrevi sobre os lugares dentro dos lugares mas depois de ter regressado à minha fortaleza. Ou seja, a escrita foi mais alimentada pela memória dos lugares que pela sua interferência física. Espero, no futuro, aprofundar este veio e escrever in situ. No meu projecto literário (ou melhor, no conjunto aberto daquilo que escrevi e que o balanço entre acaso e intenção me levar a escrever no futuro), esta geografia ampla e misteriosa é um pilar não menos importante do que a história. A bem dizer, trata-se menos de uma geografia no sentido clássico, de leitura e domesticação do espaço, e mais de uma intuição geográfica como forma de abertura ao desconhecido a que se chega por meio da viagem.

Rita Chaves: Há um traço na sua obra que encontro em outros autores de Moçambique e Angola. Trata-se de uma necessidade de explicar fatos e situações que se desenvolvem na narrativa. Parece, algumas vezes, que há uma distância entre as personagens e os leitores que o narrador precisa ocupar, o que faz,pensar na questão do leitor virtual. Como você vê o seu leitor? Essa necessidade de detalhar está ligada ao fato de ter seus livros editados no estrangeiro? Ou ela exprime a consciência de viver num contexto abalado por divisões de tantas ordens? 
João Paulo: Considero que a questão que me coloca é muito astuta, e de algum modo já me referi a ela na questão precedente, quando falava nos lugares e nos seus nomes: nomear, nomear. Nunca pensei, contudo, na questão dessa maneira. Acho que efectivamente essa "hiperexplicação" poderá ser de facto uma característica das nossas literaturas. Será que a fragilidade do nosso sistema literário (entendido como compreendendo escritores e leitores, editores e críticos) nos empurra inconscientemente para esse tipo de soluções? Será que há, nelas, traços ainda da "maneira africana" de contar histórias, herdada de um tempo tão recente, mas já longínquo em que havia de facto tempo e uma atitude de preocupação infinita e paciente com os pequenos detalhes? Será o peso que a história tem no imaginário africano? Será, enfim, um mecanismo de autodefesa dada a complexidade do putativo leitor virtual do escritor africano? Quem são os leitores do escritor africano? É um facto que pelo menos muitos de nós somos mais lidos fora do continente do que dentro. Esses leitores estrangeiros são todavia tão diversos que é difícil tentar classificá-los. Há os nostálgicos de um passado já longínquo e os que procuram o exótico, mas presumo que também haja os imigrantes, os estudiosos ou simplesmente aqueles que se interessam por literaturas diferentes. Mas é preciso dizer que a fronteira entre leitores estrangeiros e nacionais não é, a meu ver, a única fronteira, nem sequer sei se será a principal. Nos países onde escrevemos, o leitor está até mais longe de ter a homogeneidade que é característica de sistemas literários mais estabilizados. Também em Moçambique existem muitos tipos de leitores, tantos (apesar do reduzido total de leitores) que seria inútil dirigirme a qualquer deles em particular. Intuo que fazê-lo seria cair numa armadilha: "simplificar" o discurso em nome de leitores "simples" seria um exercício de um paternalismo imbecil (todos somos seres complexos, embora de maneiras distintas); tornar o discurso mais "sofisticado" seria uma presunção igualmente inútil. O que nos leva a essa necessidade de explicar? Não sei. O que posso garantir é que, pelo menos no meu caso, se trata de um processo inconsciente (no sentido de involuntário). Quando escrevo não penso de todo nesse leitor virtual. Não quer dizer que ele não exista, mas não penso nele. Sei vagamente que isso vai contra muitas teorias literárias, mas é assim. Não me preocupo de todo com essas questões, que me parecem pertencer menos à literatura que a uma sociologia do campo literário. Para mim, o acto da escrita, enquanto se processa, é um acto estritamente privado, um encenado solilóquio. Pensando 
nisso agora, talvez no meu caso o narrador tenha um papel tão sublinhado por razões de moral das quais me não consigo libertar. No mundo de hoje pouco mais nos resta que procurar sermos decentes, e acho que é com esse empenhamento que devemos exercer as nossas práticas, incluindo a da escrita. A melhor forma de sermos verdadeiros com os outros consiste em sermos verdadeiros connosco próprios, e isso vale também para a escrita. Mesmo que dentro dela essa atitude seja pura encenação conduzida por um narrador.

Rita Chaves: Há uma outra questão que se liga a essa anterior. Há uns anos atrás, Mia Couto defende em uma conferência a necessidade de o escritor se desafricanizar. Por outro lado, você deve sentir por parte da maioria dos leitores uma expectativa em relação à literatura africana. Como é que acha que seus romances respondem a essa questão?

João Paulo: Desconheço o contexto em que o Mia Couto falou em necessidade de desafricanização do escritor. A convocação da africanidade tem, a meu ver, duas razões legítimas e profundas: os três terríveis traumas sofridos historicamente pelas gentes do continente (a escravatura, o colonialismo e o apartheid), e a necessidade de afirmação identitária num mundo que tem hoje muito pouco de igualitário. Dito isso, é preciso reconhecer que hoje em dia também existe um outro tipo de apelo à africanidade que tem traços de recurso e artifício (por vezes assumindo contornos miseráveis, como por exemplo na justificação de Mugabe). Já li, de um escritor africano, que se o africano exótico é o que vende, então façamos literatura africana exótica! Acho este jogo irresponsável e muito perigoso. Podemos também olhar a necessidade de desafricanização de uma outra maneira, relativamente àquela literatura que se esgota no recurso exclusivo a putativos valores africanos, que forçosamente se torna panfletária e cai na ingenuidade e na superficialidade. Hoje em dia as fronteiras existem para serem atravessadas, além de que não é mais possível ignorar o que foi feito no passado, em termos de literatura. $\mathrm{O}$ escritor não tem outro remédio senão ser culto. Uma terceira maneira - e eventualmente será esta que refere na questão que coloca - tem a ver com preconceitos editoriais do "norte", que remetem a literatura africana para um gueto das livrarias, como o estatuto de literatura exótica ou étnica capaz de despertar curiosidades e simpatias mas, neste acto de suposto marketing, sempre menorizada. É preciso desafricanizar esta literatura face ao olhar do Outro, torná-la literatura univer- 
sal. A literatura é soberana no sentido mais essencial, e a finalidade da ficção é abrir o espaço de uma história que através da leitura possamos contar a nós próprios. Considero, algo radicalmente, que é ilegítimo qualquer propósito exterior a ela mesma. No que me diz respeito, ou a africanidade transparece nos meus textos sem ser intenção fundamental que estes têm (uma particularidade incutida pelo lugar a que pertencemos, pela maneira de olhar o mundo a partir dele), ou então simplesmente não existe. Não me move a necessidade de ter os meus textos classificados formalmente como africanos. Sou, como disse, um escritor tardio, não me resta tempo para carreiras e etiquetas. Acredito que a literatura não deve ser limitada por critérios geopolíticos ou supostas definições identitárias. Acredito que ela é soberana, que define o seu próprio campo onde cabe todo o resto nos seus próprios termos.

Rita Chaves: Uma questão que interessa muito ao estudioso das literaturas situa-se no campo da formação do escritor. Que escritores estão na base da sua formação?

João Paulo: Essa questão tem-me sido colocada algumas vezes e continuo sem conseguir responder-lhe com clareza. Não sou tomado pela "angústia da influência”, para usar a expressão de Harold Bloom. Parto para a folha branca (ou para o monitor vazio do computador) com as mãos limpas, sem preocupações de me inscrever em qualquer linha de coerência. Isso não quer dizer, claro, que as influências não existam. Hoje em dia é impossível escapar a elas e, mais do que isso, não é desejável escapar a elas. Hoje em dia não é mais possível praticar uma escrita totalmente liberta de influências, uma escrita inocente. Há um sentido de acúmulo em tudo o que fazemos, seria impossível estarmos sempre a partir do zero e a usar referências próprias, sob risco de inutilidade (o risco de não acrescentarmos nada à soma do mundo). Na literatura, é certo, esse acúmulo não se processa no sentido directo em que ocorre nas ciências exactas, susceptíveis de experimentação objectiva, mas isso não quer dizer que ele não esteja lá. Está, e em grande medida está por via da leitura. Sem dúvida que, entre tudo aquilo que influencia a ficção a própria ficção ocupa um lugar especial. A ficção é um jogo que imita a vida, e penso que é preciso ler muita ficção para nos irmos apropriando das secretas regras desse jogo (é esse o sentido de acúmulo a que me refiro). Porque, embora aberto ao extremo, a ficção é um jogo que, se lhes desrespeitamos certas regras, deixa de ter sentido. 
Um jogo que finge a sua própria verdade, e finge-a de um modo verdadeiro. Se quebramos certas regras, se não sabemos fingir, o resultado surge como se estivéssemos ingenuamente a tentar ser verdadeiros tout court, e portanto é um resultado que quebra as regras do jogo e acaba por "soar mal". Este conflito entre "verdade verdadeira" (que todavia soa a falso sob o ponto de vista literário) e encenação literária da verdade é sempre difícil e nunca inteiramente apaziguado. Isso porque o mecanismo é muito frágil, a linha de separação muito fina. Há escritores que levam esse jogo ao limite sem soçobrar, como o Ruy Duarte de Carvalho d' Os Papéis do Inglês ou o último JM Coetzee (Summertime, em que o tema é a investigação de uma fase da vida do próprio escritor, levada a cabo por um personagem literário); outros em que as intenções são as melhores, mas ingenuamente se desrespeitam as regras da ficção e tudo se quebra. Evidentemente que há ainda um terceiro caso, em que com má-fé o escritor finge aceitar as regras do jogo para fazer passar uma mentira por verdade fora do campo literário (o Dan Brown d' O Código Da Vinci). Enfim, perco-me. Voltando à questão colocada, é preciso ter em conta que, além da própria ficção, o olhar literário que conduz à escrita se alimenta de outras coisas: de poesia, da reflexão filosófica, da música e da pintura numa medida bem maior do que aquela que normalmente é tida em conta, enfim, de jornais e, acima de tudo, da observação e da reflexão que se vai fazendo sobre o mundo e sobre a vida. Pelo menos é assim que sinto "o meu caso". Quanto aos escritores propriamente ditos, é-me muito difícil desfiar nomes, tantos são eles. Uns acompanharamme na juventude pelas razões mais diversas, desde a descoberta da língua escrita e dominada com mestria (Eça), até ao mistério (Poe, Borges, Conrad) e à rebeldia (Kafka, que li sempre como um desafio ao mundo da pequena sensatez: 'Olhemo-nos ao espelho! Vejamos como somos!'). O cortejo foi crescendo, com base no que a curiosidade me levou a procurar, nas indicações de outros ou simplesmente pelo que o acaso me trouxe às mãos. A bússola é caprichosa, determina sentidos nem sempre pelas razões mais plausíveis: no sentido de um discurso quase autista, relaciono Beckett e Lobo Antunes; atormentam-me os cenários inquietos de W.G. Sebald e Lawrence Durrell; impressionam-me a agressividade da escrita de Nassar, a contenção de Rulfo; no duplo sentido das palavras estabeleço associações improváveis entre Clarice Lispector e Gonçalo M. Tavares. Enfim, leio todo o J.M. Coetzee, mestre rigoroso do desencanto e da economia do discurso; e vou lendo Proust sempre que posso ler com todo o 
vagar que a sua leitura requer, pois não conheço texto literário mais suculento do que o dele. Como se vê, o meu percurso é o percurso errático de um leitor comum que não se sente obrigado a seguir itinerários precisos ou a estabelecer ordens de sentido e hierarquia das leituras. Leio o que me dá gozo, e se há aqui uma inquietação é a de, apesar de esperar ainda viver muito tempo, já não me restar o tempo suficiente para ler ou reler tanta coisa. Mas quero ainda referir uma coisa que me parece importante: entre o que leio e o que escrevo não há uma ponte, mas antes um rio de águas fundas e insondáveis, e diz-me a intuição que é importante que permaneça assim. Não escrevo para fazer valer um ponto de vista que me tenha sido suscitado por uma ordem de leituras. Tudo o que leio me influencia, mas no momento de escrever estou longe de tudo isso. Libertei-me da racionalização de tudo isso para ficar sozinho e inseguro. É assim que vejo a escrita, com o passar do tempo mais ameaçada pela rotina, mas sempre almejando a insegurança da primeira vez. Acredito que o segredo está neste jogo em que participam a cultura, a técnica de manipulação do jogo da ficção (o seu desafio e reinvenção permanentes), o amor às palavras (não só ao seu significado mas também - para usar uma expressão de Agamben - à "substância lenhosa" das palavras quando despidas de todo o significado), o impulso que provoca a faísca que acende a fogueira, e finalmente a procura da inocência de um certo olhar.

Rita Chaves: Os problemas que cercam as questões raciais e étnicas ocupam um lugar importante nas discussões sobre os paises africanos. Como você vê essa questão em Moçambique? A despeito da pluralidade e de alguns conflitos ligados a esse fenômeno ou, pelo menos, alimentados por ele, pode-se falar numa nação consolidada?

João Paulo: O racismo é um mal social profundo baseado na recusa do diferente. É um estado em que a surpresa natural face à diferença observada no Outro degenera em recusa irracional deste e, portanto, numa espécie de doença. O continente africano é uma vítima histórica desse racismo, que deixou marcas indeléveis no seu corpo. À recusa do outro como estratégia de dominação respondeu ele muitas vezes com a recusa do outro como mecanismo de defesa, dada a sua vulnerabilidade. O racismo é uma doença que floresce (não é a palavra mais apropriada neste contexto, bem sei), tanto na miséria e na podridão como nos palácios. E é uma doença parasita porque se alimenta 
de outros conflitos e tensões, recobrindo-os, instilando neles o seu próprio veneno. Se lhe é dado um pequeno espaço ela dedica-se com afã a esse labor insidioso. Enfim, esta é uma questão demasiado séria e demasiado complexa para ser tratada en passant. Moçambique é um país cosmopolita, os dois mil e quinhentos quilómetros de costa, a presença árabe e europeia, o facto de ter sido desde sempre atravessado por corredores de passagem para o interior incutiu nele essa atitude tolerante e culta. Mas não devemos descurar o facto que a semente desse mal está sempre presente, travestida, quando os do sul recusam os do norte, quando os da costa recusam os do interior, quando se apela acriticamente à tradição (uma categoria que é acima de tudo uma construção levada a cabo no presente) para em seu nome tentar que vinguem propósitos que não há coragem para afirmar abertamente. Moçambique ainda hoje é atravessado por muitos sintomas destes; periodicamente ainda há quem ache importante enunciar as características físicas do moçambicano verdadeiro, originário. Este sintoma de barbárie existe, aliás, no resto do continente africano, tal como existe no resto do mundo (a Europa deu-nos conta dele recentemente). Neste sentido, por mais passos que se deem, as nações nunca são consolidadas, simplesmente porque essa consolidação vai no sentido não do fechamento, mas do intercâmbio e da abertura. Elas definem-se por contraste em relação a outras e, portanto, pressupõem relação e abertura. As nações são convenções, construções políticas e o que destas se sedimenta em termos culturais. As nações não são denominadores comuns ditados por atributos físicos, religiosos ou outros.

Rita Chaves: Em Crónica da Rua 513.2, a partir do microcosmo de uma rua, há um balanço muito arguto de um tempo de passagem, prenunciando certos problemas que a sociedade viria a desenvolver. Como você contaria aquela rua hoje?

João Paulo: De certa maneira este é um dos meus livros mais próximos da "História". O funcionamento lógico da narrativa historiográfica baseia-se em grande medida na tensão entre mudança e continuidade, que se confrontam com particular intensidade nos chamados períodos de transição - ou, como lhe chama, de passagem. Este livro trata da passagem do fim da era colonial para o período que se seguiu à independência. Trata-se de um olhar virado para o passado, usando ferramentas de análise que só se aplicam ao já acon- 
tecido, nunca ao que está por acontecer. São ferramentas inadequadas para o que está acontecer, e ainda mais para o que vai acontecer. Um erro comum na análise histórica consiste em encarar o futuro como uma certeza. Todavia, o futuro é cego, depende das obras que fazemos no presente, depende da conjugação de vários factores, muitos deles inesperados e impossíveis de prever. Podemos conjecturar, podemos até adivinhar, mas não podemos dizer com certeza o que vai acontecer. Tudo isto para dizer que a rua a que se refere continua em transição, sem sabermos ainda em que estabilidade vai desembocar. No período que vai desde o tempo que o livro narra até ao agora, é certo que a rua amadureceu. Hoje descrevê-la-ia com mais regras, menos abusos de poder e arbitrariedade, mas também com muito menos solidariedade entre os moradores. Vivemos um tempo paradoxal muito difícil de interpretar, em que há claros avanços materiais acompanhados de inquietantes sinais da possibilidade de retrocessos políticos. De certa forma a profecia cumpriu-se: os muros que separam as casas estão muito mais altos.

Rita Chaves: Percebe-se que há nesse momento uma espécie de explosão de memórias. $V$ ários personagens da história recente do país têm oferecido a sua visão de acontecimentos importantes vividos ou imaginados por eles. Qual a importância desses relatos na composição da macronarrativa nacional?

João Paulo: As memórias (mais ainda as memórias escritas e publicadas) são sempre construções, mesmo se imbuídas de elevado grau de sinceridade. Do ponto de vista técnico da história são fontes como outras e não revelações sobre o "passado verdadeiro". As memórias nada nos dizem sobre a verdade, dizem-nos apenas o que quem as escreve vê, ou o quer que seja visto como verdade. Tanto quanto respeitando ao passado, elas devem ser vistas como respeitando ao presente, ao que se quer que seja visto no presente como tendo sido o passado. As memórias são fontes para estudar o período a que se referem e para estudar inclusivamente quem as redige. Uma vez definido, no meu entender, o sentido dessas memórias, passemos agora a esse fenómeno de "explosão". Penso haver várias razões por detrás dele. No caso moçambicano (e já o referi várias vezes) a memória do período de libertação nacional tem sido fundamental para ordenar o presente, no sentido de legitimar um sistema. Dada esta importância, tem sido internamente muito mais objecto 
da memória política (no sentido de memória gerida pelo político) do que pela memória historiográfica da academia, ou do que por outros tipos de memória que também se configuram na paisagem, nomeadamente a memória comunitária ou a memória individual. Salvo algumas excepções, as memórias que integram a explosão de que fala inscrevem-se nesse movimento de legitimação da memória política dominante, e visam o período da luta de libertação nacional ou aquilo que aqui por vezes se designa de "Primeira República". O académico búlgaro Ivaylo Znepolski diz que a gestão política da memória se traduz de duas maneiras principais: ou na gestão do esquecimento ou na convocação excessiva e insistente de um determinado tipo de lembrança a fim de a manter num nível superficial e controlado. Quanto àquilo a que chama a macronarrativa nacional, ela resulta da tensão e dos conflitos entre as várias memórias e está para além do que a memória política é capaz de gerir. Ela estabelece-se na longa duração, e portanto, embora fazendo parte dela, estes testemunhos têm uma influência muito relativa.

Rita Chaves: Com exceção de As duas sombras do rio, em que temos a guerra como uma presença concreta, em seus outros livros ela é mais insinuada do que encenada. Como você acha que essa sucessão de guerras que o país viveu está presente no imaginário nacional, levando em conta, inclusive, as fraturas que caracterizam o país?

João Paulo: Pelo que atrás ficou dito, não creio que exista um só, mas vários imaginários nacionais, imaginários esses que estabelecem tensões entre si e alimentam, na "longa duração", a tal macronarrativa nacional que se refaz incessantemente. No imediato, e tendo em conta o estado preliminar da historiografia nacional, a memória colectiva tem sido gerida com crescente empenhamento e vigor pela categoria do político, que procura convocar excessivamente a memória do conflito de libertação e "apagar" o conflito civil da década de oitenta, praticamente inexistente no espaço público. Esta situação não é de estranhar, uma vez que todos os regimes gerem a memória. Acho, todavia, que é dever daqueles que nos conduzem desdramatizar esta questão muito mais do que aquilo que tem sido feito, o mesmo é dizer que é seu dever neutralizar a relação directa que se possa desenhar entre as interpretações do passado e aquilo que refere como as fracturas que dividem o país. Tendo em conta as definições democráticas estabelecidas constitucionalmente, é neces- 
sário abrir arquivos e dar mais espaço a um conflito saudável entre as diversas memórias que nós temos. No que diz respeito à minha literatura, sem dúvida que ela procura participar nesse debate, mas dentro dos limites muito claros de que não é esse o seu objecto. De resto, os conflitos perpassam os meus textos não só naquele que referiu, mas em muitos outros (por exemplo, a narrativa "As cores do nosso sangue", inscrita nos Índicos Indícios). É importante frisar que não pretendo, recorrendo à literatura como eventual instrumento, entrar num debate determinado pelo político. Reafirmo que o objecto da literatura é, para mim, definido no seu próprio campo.

Rita Chaves: O romance premiado no Concurso LEYA aponta para novos modos de localizar Moçambique. A relação com os países à volta quebra a monocórdica inserção do pais no conjunto da chamada lusofonia. O seu trabalho como bistoriador envolve a questão da regionalização. Como o escritor analisa essa relação que será certamente trabalhada pelos estudiosos?

João Paulo: A questão que aponta inscreve-se efectivamente na intenção do livro: fugir às explicações essencialistas (Moçambique como resultado exclusivo de si próprio) ou "lusófonas" (Moçambique como resultado exclusivo da língua ou das ligações ao mundo imperial português). A história deste país está intimamente ligada à região (ou hinterland, como aqui se diz). Se há uma estrutura que explica a colonização neste lugar é o sistema ferro-portuário e o trabalho migratório como componentes que permitiram que ela sobrevivesse servindo o desenvolvimento da África do Sul e da Rodésia. Moçambique não existiria, de facto, sem a região onde está inserido, e esses anos de viragem para o século vinte, de que o livro trata, são decisivos na configuração do território. Todavia, não considero que este romance seja um romance histórico no sentido da reconstituição ou da explicação de um período da história, ou sequer da inserção de uma trama num período histórico. É antes um "flirt" com a História no sentido em que, com a mesma força com que a reconstrói (palavra enganadora, uma vez que o tempo é incapturável) também a falsifica. É um livro que, situando-se com algum rigor no contexto do que aconteceu, indaga ao mesmo tempo sobre o que poderia ter acontecido. Se me perguntasse o que pretendi com o livro, dir-lhe-ia que, muito antes de circunscrever um período histórico quis evocar essa personalidade contraditória e extra- 
ordinária que foi João Albasini, entender essa personalidade romântica que foi Von Lettow-Vorbeck, esmiuçar a saga rocambolesca dos Foster, notórios bandidos que agitaram a África do Sul desses tempos. E, sobretudo, homenagear a cosmopolita cidade de Lourenço Marques da altura, passear pelas suas ruas, olhar os seus edifícios, estabelecer percursos que tal permitissem (mais uma vez os lugares e os caminhos que os devassam); enfim, mostrar que, embora por meios mais difíceis e demorados, o mundo estava já nessa altura todo ligado. Recorrendo a uma analogia com a pintura, peguei em imagens nítidas e fui-as desfigurando. No fundo, procurei experimentar o prazer de contar uma história. 